\title{
Social Networks and Educational Mobility: the experiences of UK students
}

\author{
Rachel Brooks and Johanna Waters
}

\section{Globalisation, Education and Societies (2010)}

\section{Abstract}

A recurrent theme in the literature on transnational mobility - and particularly that pertaining to the young and/or highly skilled - is the individualised nature of such movement, as people move to take advantage of opportunities in an increasingly interdependent world. Drawing on research with 85 young adults who had moved overseas for their higher education, or were seriously contemplating doing so, this paper subjects this claim to critical scrutiny. Indeed, it suggests that while internationally mobile students are clearly only a subset of the broader category of transnational migrants, they nevertheless demonstrate important ways in which mobility is often socially-embedded, grounded within networks of both family and friends. It then points to the socially reproductive nature of such ties, and discusses their implications for the development of 'mobility capital'. 


\section{Introduction}

Over recent years, the UK’s position on 'international education' has undergone a significant shift. Until 2006, the emphasis within higher education policy was very much on increasing the attractiveness of the UK as a destination for students from other countries and boosting the number of non-European Union students within British universities, predicated largely on economic arguments. Since the launch of the second phase of the 'Prime Minister's Initiative on International Education' in 2006, however, more emphasis has been placed on the benefits to both UK students and staff of increasing the opportunities for outward mobility (i.e. spending some time at a higher education institution overseas) - in terms of developing intercultural skills and a more cosmopolitan outlook (DfES, 2006). Alongside this small but significant policy shift, we have witnessed increasing interest from UK students in overseas study. The Fulbright Commission has reported high demand from schools and colleges for information about study in the US (Shepherd, 2006), while the number of UK citizens enrolling in American universities has also increased (Institute of International Education, 2007). Moreover, press reports have suggested that European universities are becoming increasingly attractive to UK students, particularly those that offer no- or low-fee courses (Clark, 2006).

Despite this policy focus and the burgeoning of studies on transnational migration, there is still relatively little research on the motivations and experiences of students who move abroad for their higher education. Furthermore, the majority of the work that has been conducted in this area has focussed on East to West migration and, in particular, on movement from Asian countries to Anglophone destinations such as the US, Canada, Australia and the UK. We 
thus know little about either the motivations or the experiences of students from richer, Western nations who pursue a higher education overseas. In this paper, we hope to begin to address this gap by focussing on UK students who choose to study abroad for the whole of an undergraduate or postgraduate degree. While this is inevitably a relatively small group, the evidence cited above suggests that it may well be one that is of increasing importance to UK policymakers, as well as to overseas institutions themselves.

In this paper, we draw on data collected for a British Academy-sponsored project, based on in-depth interviews with 85 young adults. Our in-depth interviews with respondents were wide-ranging, and included questions about their family life, networks of friends and educational histories. In this way, we were able to explore some of the wider and more diffuse influences that may impact upon a decision to pursue overseas education. During the analysis of the interview data we became sensitive to the impact of social networks on decision making processes, in particular; and this forms the central focus of this article.

After briefly outlining our sampling methods and the characteristics of our achieved sample, we highlight some of the ways current debates on transnational mobility are often framed by assumptions about the individualised nature of such movement and the capacity of individuals to move freely to take advantage of opportunities within a globalised world. We then draw on our dataset to subject these assumptions to critical scrutiny. In particular, we suggest that while internationally mobile students are clearly only a subset of the broader category of transnational migrants, they nevertheless demonstrate important ways in which mobility is often socially-embedded, grounded within networks of both family and friends. We go on to point to the socially reproductive nature of such ties, and discuss their implications for the development of 'mobility capital'. 


\section{The young adults involved in the research}

Our research was designed to explore the motivations of students moving abroad for the whole of a degree. We were keen to include both undergraduates and postgraduates in our sample, and those seriously contemplating such a period overseas, as well as those who had completed a degree abroad. Respondents considering overseas education were recruited through a wide variety of means including: mailings and phonecalls to schools and careers offices; a visit to a higher education fair organised by the Fulbright Commission; email and intranet advertisements at the universities of Surrey, Liverpool and Leeds; and Facebook groups. We interviewed 40 young people in this category: 20 sixth-formers considering studying overseas for an undergraduate degree, and 20 undergraduates contemplating postgraduate study in another country. Young adults who had completed an overseas degree were recruited through: contact with 65 alumni associations of overseas universities and the Canadian Rhodes Scholars Foundation; the directory of past scholars, published by the Commonwealth Scholars Commission; mailings and phonecalls to the human resources department of companies listed within the FTSE 100; advertisements circulated to staff at a number of universities; and 'snowballing' via our own personal contacts. We interviewed 45 young adults in this category: 11 who had completed an undergraduate degree abroad and 34 who had been awarded a master's or doctoral degree from an overseas institution.

The characteristics of our achieved sample are obviously influenced by our means of recruitment. This is particularly so at the institutional level, in that the schools and universities that were most helpful to us, in terms of contacting students and/or sending our emails on our behalf, are better represented in the overall sample. Nevertheless, our sample is reasonably diverse in other respects: overall, we interviewed 48 men and 37 women, and 22 
respondents were from minority ethnic backgrounds. The social class of our sample is more homogenous: the majority of our undergraduate sample (those who were seriously considering studying abroad for a bachelor's degree or who had already completed a first degree overseas) came from privileged backgrounds and had attained a high level of academic qualification, often in private schools. Indeed, 19 of the 31 respondents in our undergraduate sample had attended a private school. Our postgraduate sample was, however, significantly more socially diverse and included many more students from lower socioeconomic groups and who had experienced more varied educational histories. Of the 54 interviewees in this group, only 12 had attended an independent school. Individual, in-depth interviews were conducted with all 85 respondents between September 2007 and February 2008.

\section{Individualised nature of many accounts of transnational mobility}

Much of the extant literature on transnational mobility places considerable emphasis on the largely individualised nature of this movement. This is particularly evident in relation to the mobility of more privileged groups in society: while the family networks of lower-skilled labour migrants are often highlighted, their higher-skilled counterparts (such as Sklair’s (2001) 'transnational capitalist class') are frequently portrayed as moving in more independent, autonomous ways and as less firmly embedded within familial networks. For example, Fechter (2008) suggests that in terms of the mobility of women in particular, recent years have witnessed a shift from 'incorporated wives' - those who follow their husbands from one overseas posting to another, and whose (unpaid) labour is often an implicit part of the contract between the employer and (male) employee - to 'expat girls' - young women 
who seek employment abroad under their own initiative, are usually single and frequently claim to be 'trailblazers', establishing new patterns of female mobility. Similarly, in their analysis of young British professionals in China, Willis and Yeoh (2008) contend that women are increasingly involved in skilled migration in their own right and often see such a move as freeing themselves from constraints experienced at home such as economic problems, lack of career progression and pressures from family members.

This emphasis on discontinuity with previous social networks is central to Kennedy’s (2004) analysis of the friendship patterns of transnational professionals (in this case, working in the building design industry). He maintains that there are significant differences between transnational professionals and other types of migrant in terms of the sociality they create, with the former developing new forms of friend relationship as a result of the particular living and working conditions they experience. Indeed, he suggests that 'transnational social spaces may encompass and generate more social units of analysis than are presently available in the sociological repertoire’ (p.161). Here, Kennedy is not suggesting that mobile professionals live more individualised lives than others. He does, though, argue that pre-existing networks of family and friends have relatively little role to play in motivating mobility in the first place, and then in the day-to-day sociality of such professionals once they take up a job abroad. A similar theme pervades Mazlish and Morss' (2005) analysis of the 'global elite' those who lead multinational corporations. Indeed, they contend that such workers 'increasingly see themselves as cosmopolitans, as global citizens, with an identity that...transcends the nation-state and its restricted sense of territoriality’ (p.171) and are thus unlikely to feel strongly embedded in domestic community or familial networks. 
This implicit (and sometimes explicit) emphasis on the individualised nature of many decisions to travel abroad to seek employment is also evident in numerous accounts of youth travel. Desforges’ (2000) discussion of the reasons why young people embark upon long-haul travel is typical of much of the literature in this area. He argues that, for many, travel is a resource that is drawn upon at critical moments, 'when self-identity is open to question', as a means of 're-imagining' the self (p.933). Moreover, he suggests that, for his respondents, 'travel played a relatively powerful role in helping them to feel as though they were moving towards a rewarding self in the future' (p.935) and that the experiences they accumulated en route were often used in a creative manner to 're-narrate and represent self-identity' (ibid.). This articulates clearly with theories of individualisation and the argument that, under the conditions of late modernity, we are all under pressure to construct reflexively our own ‘biographical projects’ (Giddens, 1991).

Nevertheless, despite this body of evidence that has placed considerable emphasis on the individualised ways in particular groups of migrants (namely the young and/or the highly skilled) are motivated to seek work and other experiences overseas, our data paint a significantly different picture. Indeed, the narratives of our respondents highlight the sociallyembedded nature of educational mobility and the importance of various kinds of social networks in explaining how and why young adults in the UK decide to move abroad for their tertiary education. While many of our respondents were clearly highly independent young people, confident at moving away from immediate family and friends to pursue a relatively unusual type of education, a large majority were, nevertheless, located within kinship and friendship networks that valued mobility highly and could thus provide both practical support and a high degree of positive affirmation of such choices. The specific ways in which this influence was played out are outlined in the next section of this article. 


\section{The influence of social networks}

\section{Kinship networks}

While educational mobility remains an under-researched area, an important focus of much of the extant literature in this area has been the role of the family in facilitating migration. In large part, this has emphasised the very strategic manner in which parents and other family members approach educational decision-making, and the ways in which an overseas education is often understood as a means of securing advantage for the whole family. For example, in their research with Chinese students studying at Australian universities, Singh and Doherty (2008) maintain that the decision to pursue tertiary education in Australia was often made 'by the patriarch of the family' (p.123) with the primary purpose of extending the network of transnational familial alliances. Drawing on Ong's (1999) work, they go on to suggest that such investments in Asian diasporic spaces are often driven by a 'transnational imaginary’ which is developed by the whole family. Indeed, Ong has argued specifically that, for Chinese families, international education is not only an important class marker (see also Singh et al., 2007), but also often provides an entry point to western democracy for the extended family. Indeed, she claims that various sacrifices are made to achieve these ends: 'familial regimes of dispersal and localization [in pursuit of an overseas education].... discipline family members to make do with very little emotional support; disrupted parental responsibility, strained marital relations and abandoned children are such common circumstances that they have special terms' (1999, p.128). Similarly, on the basis of her work in Hong Kong, Waters (2007) argues that with an increasingly competitive domestic education system, middle class families are less sure about their ability to maintain their 
social advantage through monopoly of the best schools and colleges. Instead, she contends, they look to overseas education as an alternative means of securing 'distinction'. Similar family strategies have been documented in other Asian countries: for example, Pimpa (2005) argues that Thai young people from families with experience of overseas education are subject to higher family expectations to study abroad than others. In this way, familial norms come to assume a significant role in educational decision-making.

While the majority of studies of such family 'strategies' have focused primarily on migration from East to West, Moore’s (2008) analysis of the role played by the German School in London provides a useful counterpoint, demonstrating how international education can be pursued instrumentally even by Western families with considerable cultural capital. Indeed, she argues that: 'by encouraging the[ir] children to view international networking as positive, and exposing them to the cultures of German multinationals, the parents are ensuring that the children develop skills, contacts and interests in keeping with those of an expatriate elite' (p.99). Recent research amongst British nationals has certainly highlighted very similar ‘strategic’ approaches to parenting. Indeed, Vincent and Ball’s (2006) study of middle class parents and their children demonstrates some of the ways in which childcare and childrearing practices:

....are joined up within processes of the social reproduction of families. That is, they involve investments, within the child, both in the accrual of class resources...and in terms of the realisation over time of particular selfhoods and personalities. (p.159)

They go on to suggest that the strategic way in which middle class parents make decisions for their children is both an enactment of class relations and an act of reproduction, 'focussing on 
the future and equipping the child with the social and educational resources deemed necessary by families within particular social groups’ (p.167). In many ways, this accords with Beck and Beck-Gernsheim’s (1995) assertion that parenting in contemporary society is no longer based on an unconditional acceptance of the child as it is; instead the child becomes a 'project', the focus of parental effort. Nevertheless, within our own research, we found very little evidence of this kind of familial influence in relation to decisions to pursue an overseas higher education. (There are, of course, numerous studies that point to the strategic approach of families when choosing a UK-based higher education for their children, for example, Reay et al, 2005.) In contrast to many of the studies cited above, the influence of parents and other family members was subtle and often implicit. However, it often tended to have the same effect: notably the reproduction of social advantage. This was achieved through the development of a habitus (Bourdieu, 1977) in which it is considered 'normal' to travel, and an associated degree of confidence at dealing with new cultures. Amongst our respondents, there appeared to be three main ways in which such dispositions were inculcated. Firstly, many of the young adults in our sample described how they had travelled a lot as children during family holidays. Felix’s comments are broadly typical of these narratives:

Interviewer: What kind of places have you been to?

Felix: $\quad$ Not all over Europe but quite a lot of Europe, some bits of America, Southern Africa, just South Africa, Namibia, Botswana. .... My parents I guess are quite adventurous in their travelling, probably stemming from stuff they did when they were younger and maybe taking the last kind of five or ten years ago, financially were able to do it, so they've taken us to far further ranging places. 
Interviewer: And how do you think that's affected you as a person?

Felix: $\quad$ It's given me a massive taste for travelling.....

(Felix, planning to study MA in Geological Sciences at Wellington University, New Zealand)

This accords with other research from the UK, which has suggested that students who have travelled (or lived) abroad before they entered higher education are more likely than their peers to engage in formal mobility during their time at university (Sussex Centre for Migration Research, 2004). Furthermore, some of the studies of Asian families noted above have also pointed to strong associations between family travel and propensity to pursue an overseas higher education (Singh et al., 2007).

Secondly, a smaller number of our respondents had had significant experience of overseas travel as a result of their parents' work. They bear some resemblance to the 'globally mobile children’ or 'third culture kids’ described in Hayden’s (2006) typology of students who pursue an international education. Harriet (a sixth-former, hoping to study history of art or business in the US) is typical of this group in explaining how her time living abroad affected her attitude to travelling more generally:

Harriet: $\quad$ I lived in Hong Kong....My dad's firm have offices all over the world and he was asked to go out there for three years and then they added an extra year on the end, so we went out and that's where I started primary school .....

Interviewer: OK and how do you think that experience has influenced you? 
Harriet: $\quad$ I love travelling and I love going to see different places and I've travelled quite a lot since then, like we go on holiday and I've been back to Hong Kong a couple of times.

Thirdly, some of our sample had one or more parent who had been born overseas, and who had retained strong links to that country. However, in keeping with the profile of our overall sample, such immigrant families tended to come from richer countries and from relatively prosperous socio-economic groups. Furthermore, the majority of our respondents from transnational families were clearly comfortable at conducting relationships across national borders and drawing on transnational connections where useful.

Interviewer: Why are thinking about studying overseas?

Alecia: I think because of my mother and my mother's family, I’ve had, I've been lucky I've been given a lot of opportunity to go to America and different parts obviously but I've had more than a taste of life there because I spent most of my holidays there with the family.....

Interviewer: So you've still got family in the US?

Alecia: $\quad$ Yeah....my grandmother lives in Connecticut and so I probably, you know I preferably would like to go somewhere in New England so I'd have her there if I needed her there sort of thing and she's like completely capable, she’s not like an old biddy, she’s still working and like driving and everything. So if I did go to university it would be in New England so I'd know I could get on a train and like in two or three 
hours I could be somewhere, if I went somewhere near that area sort of thing.

(Alecia, sixth-former planning to study history or English in the US)

Here there are again parallels with previous UK-based research. In his analysis of students who take part in short-term overseas exchanges, King (2003) notes that a third of his sample had an international family background, with at least one parent of non-UK nationality. Nevertheless, it is important not to assume that the various family experiences described in this section of the paper determine young people's decisions about educational mobility. While they may certainly help to widen students’ 'horizons for action’ (Hodkinson, 1998), the variety of decisions taken by siblings from the same family cautions against an overly simplistic reading of familial influence (Murphy-Lejeune, 2002).

\section{Friendship networks}

Friend-relationships have, historically, tended to be overlooked within sociological study (Jamieson, 2005; Adams and Allan, 1998). Moreover, some contemporary critiques of society have suggested that, as a result of the corroding effects of individualisation, social life has been fragmented - with friendship suffering, alongside other types of communal ties (Bauman, 1995; Putnam, 2001). Nevertheless, this analysis is not accepted by all. Spencer and Pahl (2006), for example, have argued that social connections, including friendship, remain very important even if, as a consequence of the decline in face-to-face contact, they are less visible than in the past. They emphasise the wide variety in the repertoire of the friendships people sustain, ranging from soulmates to much more casual relationships, and 
also the spatial variation in the arenas in which friendships are played out. Indeed, Spencer and Pahl maintain that friends are increasingly able to sustain significant non-local relationships over both time and space. Within our sample, friendship networks were significant in influencing educational mobility, although this was rarely in a direct and explicit manner. Instead, they contributed to a wider youth culture in which travel was valorised and the maintenance of long-distance friendships was relatively commonplace. Furthermore, friends also provided links to specific countries or institutions for study, and thus helped to minimise young people’s fears of the 'unknown'. Both of these are now discussed further, drawing on examples from our dataset.

Numerous scholars from across the social sciences have documented the ways in which travel (and particularly to long distance destinations) has become an important part of youth culture. In some analyses this is bound up with developing a 'narrative of the self' and 'biographical projects' (Desforges, 2000); in others, it is linked more explicitly to the accumulation of cultural capital and labour market advantage (Heath, 2007). Moreover, Conradson and Latham (2005) maintain that for many people, not only the young, a period living abroad is becoming an increasingly normal and almost taken-for-granted part of the lifecycle, closely linked to a culture of self-development and self-exploration and predicated on the more general process of societal individualisation. Certainly, within our sample, there appeared to be a widespread valorisation of travel amongst the peer groups in which our respondents were located: moving abroad for higher education thus tended to be viewed very positively. In this extract, for example, Jennifer implies that her friends’ positive experiences had helped to reinforce her own decision. 
Jennifer: $\quad$ Australia has always appealed to me. Also last year I had in my office a few people who had actually been travelling and had been to Australia....

Interviewer: And how have your friends been talking about their time in Australia and around the world?

Jennifer: $\quad$ Loved it, absolutely it, I mean they both loved travelling so much that, no, especially one of them they loved Australia, that kind of area, New Zealand....

Interviewer: How do you feel that's influenced your decision?

Jennifer: I've found out more about Australia and things like that, where it's kind of the positives and the negatives side.

(Jennifer, planning to study for an MA in International Marketing in Australia)

In his analysis of migration in contemporary society, Appadurai (1996) argues that: 'the imagination has now acquired a singular new power in social life....more persons in more parts of the world consider a wider set of possible lives than they did before'. While suggesting that the media has played a key role in facilitating this change, he also contends that 'important also are contacts with, views of and rumours about others in one's social neighbourhood who have become inhabitants of these faraway worlds' (p.53). The increasingly geographically dispersed nature of friendship networks has also been highlighted by a number of other commentators (Chambers, 2006; Urry, 2007). Indeed, Castells (2001) goes as far as to claim that such networks offer individuals new control over their lives through the 'new communities of belonging' that are generated as a result. The narratives of our respondents suggest that such contacts were indeed important in making overseas 
institutions seem less 'unknown' than they would perhaps have been otherwise (see also Szelenyi, 2006). For example, in this quotation, Jasmin explains how a friend who had gone to the same Canadian institution before her had 'smoothed the route':

Interviewer: OK, so when did you seriously start thinking about studying abroad? Jasmin: I think the catalyst was actually my friend John who is the year above who went over to Canada.... we were really close friends in my first and second year and then in my third year he'd gone to Canada. ..... I just thought it would be great fun to go and spend some time with him and I knew he was having a really good time and made some very good friends in Canada, so that was definitely a big factor I would say. And it just gives you that comfort, doesn't it, when you someone else has sort of done something? It sort of smoothes the route.

(Jasmin, MA in Geography, University of British Columbia)

However, in contrast to some of the assumptions that underpin Appadurai's work, we suggest that such contacts are not equally distributed amongst all young people, and that those from more privileged backgrounds were more likely to have such networks of dispersed friendship ties than their peers from more modest homes. To some extent, this was a direct result of the mediating influence of domestic educational institutions. In our sample, we have numerous examples of how 'top' independent schools and Oxbridge colleges played an important role in facilitating student mobility by offering up role models of former students who had gone on to pursue an overseas education. For some of our respondents, knowing that someone 
from their school or college had gone on to study abroad had been a source of considerable reassurance.

Linda: $\quad$...my friends who are over there at the moment, they're all having a really good time, so ...

Interviewer: OK, so have you got friends who are there already?

Linda: $\quad$ I have a few, yeah......Sort of scattered all over the place.

Interviewer: OK, so is it quite common for people from your school to go to other countries to do their degrees?

Linda: $\quad$ Mainly America... generally I think there were about, from my school say five who went this year to America.

(Linda, sixth-former at a prestigious independent school, planning to study English in the US)

Edgar: $\quad$....a couple of other people from the same college had done, had gone from Oxford to do Masters and they both had gone on to do PhDs...at UBC [University of British Columbia].

Interviewer: What sort of picture did they paint about studying there?

Edgar: $\quad$ Really positive and it was useful to have those kind of contacts as well because I think less important to me was sort of the sort of academic side, you know from the university or in the department because I think you hear and sort of pick up things, you sort of read people’s stuff, you get a sense of who is there and what they're about. But in terms of you know what it's like being a post grad student, what the 
sort of post grad community is like, where's best to live, how people cope moving away and sort of coming backwards and forwards, what are they doing for research degrees.

(Edgar, MA in Geography, UBC; undergraduate at Oxford)

In this way, we see the establishment of small-scale 'migration systems', systems which 'typically reduce the costs of mobility by giving individual movers access to the experiences of others, and social networks that encourage their movement by reducing transaction costs...helping you to find a job, a place to stay and friends when you arrive' (Favell, 2008, p.75).

Thus, while, in some cases, transnational mobility may help to inculcate new forms of sociality (Kennedy, 2004), the data from our study suggest that more traditional forms of friendship play an important role in facilitating an overseas education. Here, there are clear parallels with Conradson and Latham's (2005) research on the migration of young New Zealanders to London. They maintain that the friendship networks of their respondents were instrumental in bringing them to London, and then in helping to shape the kind of lives they led while residing in the UK. Indeed, on the basis of our data, we would concur with their conclusion that the role of young people's friends in transnational mobility, 'gives us cause to re-evaluate the traditional view of long-distance migration as a matter of an individual being disembedded from their community’ (p. 297). 


\section{Partners and other romantic relationships}

It has been argued that one way in which mobility for higher education can be framed theoretically is by drawing on literature on geographies of consumption and, in particular, on youth mobility cultures, encompassing gap year travel and the increasing prevalence of other types of long haul leisure travel (Findlay et al., 2006). This argument is taken further by Murphy-Lejeune (2002) in her research on educational mobility within Europe. Indeed, she suggests that there may be a 'critical age' for such types of migration. Her argument is based on the assumption that there is a 'sociological threshold of youth' (comprised of traditional markers of adulthood such as taking up full-time employment and embarking on a long-term relationship) and that, once this has been crossed and a young person has entered adulthood, travel becomes more arduous. Further, she speculates that those who have experienced such markers of adulthood 'and nevertheless set forth for the adventure' run the risk of 'experiencing this parenthesis in their life [the period of overseas education] in a negative way' (p.75).

While this argument seems to be based on evidence from a relatively small number of respondents in Murphy-Lejeune's study who had difficulty balancing their commitment to a partner based at home with the demands of their overseas education, our research with a significantly larger sample of young adults suggests that, far from impeding educational mobility, partners and other romantic attachments often played an important facilitative role. For a number of our respondents, such as Melissa and Fergus, the influence of a partner appeared to have been central to their decision-making: 
My husband, he wasn't my husband then he was just my partner, he’s Swedish and we went to Sweden...most Christmases and in the summer for a bit, and I really liked it and I had been learning Swedish just because we spent time there and I was quite keen to live there or see if I liked living there. So we decided that we would go after he had finished his MA and he would try and get a job there and we would, yeah, see what it was like and I would improve my Swedish and we'd see if we wanted to settle there. And so partly because of that...I started looking at the universities near where we would be living to see if there were courses that would appeal.

(Melissa, MA in Viking Studies, Uppsala University, Sweden)

I started planning [my MA] in my fourth year after I came back. Yeah it was a bit of an interesting one because I'd started thinking about it, actually thinking probably..., in my third year for probably all the wrong reasons! I was still going out with my Australian girlfriend...and that was serious and thinking of ways that I could, we could actually be in the same place at the same time really. So I guess that was when the initial research started.

(Fergus, MA in Strategic Affairs, Australian National University)

For others, boyfriends and girlfriends may not have prompted the initial decision to study abroad, but did have considerable influence on the choice of country and/or institution, as these extracts illustrate:

I've also travelled like to Canada as well and I've thought about Canada but I actually have a boyfriend now in America so that's kind of, not the biggest reason because I'd still go even if he wasn't there, but I just really want to go there. ..... I think all the 
universities I’ve applied to, ...they're really well known universities...but I feel it's more kind of location, it's near to like, it's nearer to my boyfriend's like family and it's near to a lot of like our friends.

(Leanne, planned to study for an MA in Education in the US)

There was somebody in particular that I wanted to get back to Canada to meet up with..... it sort of sealed the deal for me, it was, when I came back to do my final year in Newcastle, it was a student from Canada who came over to do the exchange from their end, so she was there to do the second year and romance blossomed!.... I mean it wasn't the only reason but then that on top of everything, I mean that was the clincher you know.

(Ross, MA in Film and Video, York University, Canada)

Evidence such as this raises questions about the validity of Murphy-Lejeune's conclusions, but also points to a further way in which social networks appear to play an important role in stimulating decisions to pursue a higher education overseas. As such, it tends to support Favell's (2008) work on migratory decision-making within Europe. He argues that romance can have a significant impact on such choices - often alongside career factors - and can also change students' outlook on the world, more generally, suggesting that they 'Europeanise themselves as they date each other in multiple dual-national combinations’ (p.67). Furthermore, there is some evidence to suggest that an attraction to others (as partners or friends) who are or have been internationally mobile may become self-perpetuating. Respondents in Kennedy’s (2004) study, for example, were 'likely to retain a preferred lifestyle orientation towards relationships with others who have been immersed in similar transnational experiences’ (p.176). 


\section{$\underline{\text { Discussion }}$}

For the purposes of this article, we have tried to disentangle the influence of friends, family and partners, to explore the multi-faceted ways in which social networks can impact upon a decision to study overseas. On the basis of our evidence, we suggest that the emphasis on the individualised nature of transnational mobility, which is a recurrent theme in much of the literature on more privileged and younger migrants in particular, is misleading. Instead, we have argued that decisions about whether to move overseas to pursue a higher education are strongly embedded within social relationships - with parents and other family members; with friends at school, college, work or overseas; and, for a considerable number of our respondents, with boyfriends, girlfriends and partners. It is, however, important not to lose sight of the overlapping nature of many of these influences. For example, the valorisation of travel within certain peer groups, discussed above, is in many cases closely related to the family background of the students: those who have been brought up in a household in which travel is highly valued and family income has been sufficient to fund family holidays and school trips are clearly more likely to infuse their peer group with similar values.

Just as there are important linkages between the different elements of a student's social network, so there are clear connections between the 'mobility capital' possessed by the young adults involved in our research and the other types of capital to which they had access. Murphy-Lejeune (2002) defines mobility capital as a 'sub-component of human capital, enabling individuals to enhance their skills because of the richness of the international experience gained by living abroad' (p.51) and argues that it is comprised of four main elements: a student's family and personal history; their previous experience of mobility, including language competence; their first experience of 'adaptation' to another culture; and 
the features of their own personality. While we would argue that this concept is a useful one, in pointing our attention to the importance of both family background and previous experiences of travel, we would suggest that the way it is defined by Murphy-Lejeune downplays both its socially reproductive effect and its interactions with other forms of capital. Instead of understanding it as a sub-component of human capital, we suggest that it is better conceptualised as a form of capital which exists alongside the others identified by Bourdieu (1997) (economic, social and cultural) and which can be both converted into these other types and produced by them. For example, economic capital is often crucial in funding travel (and fees at overseas universities), but may also be important in paying for a private schooling where friendship networks and institutional habitus may help to facilitate educational mobility in the ways we have discussed above. Similarly, cultural capital, such as familiarity with other countries, derived from frequent travel with one’s family, can clearly have an important bearing on a student's inclination to move abroad to pursue a degree. Thus, we would support Findlay et al.'s (2006) claim that:

Mobility cultures increasingly shape the motivations, aspirations and behaviour of students, encouraging many to experience foreign places through travel and for study or work reasons. Such values are culturally derived. In the context of the UK, a different social discourse appears to exist among young people from middle class white backgrounds, compared to those from working class and non-white groups. (p.314-5)

Conversion from what can be viewed as 'mobility capital' to other types of capital is also well documented by previous studies on educational mobility. Wiers-Jenssen (2008), for example, suggests that mobile students are more likely than their peers to secure a job abroad 
on graduation. A similar point is made by Rivzi (2000) who argues that young adults who have studied abroad: often come to perceive the world as dynamic and multicultural; operate within a hybridised space; and are comfortable working across a number of different cultural sites - attributes which, he suggests, may well be rewarded within the workplace. Focussing on UK graduates, in particular, Findlay et al. (2006) contend that the mobility capital achieved or enhanced through overseas education can subsequently be deployed over the lifecourse for personal, social or career enhancement. Indeed, they claim that student mobility between western nations 'can be interpreted as training for professionals and managers destined for an international career in global corporations and other transnational organisations' (p.293).

Thus, it would seem that while the concept of 'mobility capital' offers considerable analytical purchase on the ways in which an overseas education can advantage an individual in later life, it should be seen as firmly enmeshed with the other types of capital outlined by Bourdieu. Moreover, the socially reproductive nature of educational mobility should not be under-estimated. By drawing on the narratives of the 85 young adults involved in our research, we have shown how decisions to move abroad for higher education are rarely taken by free-floating individuals, but are usually firmly grounded within networks of family and friends. In this way, family values tend to be passed on and particular dispositions towards travel are reproduced. In analysing patterns of contemporary migration, Appadurai (1996) suggests that, while 'some of the force of Bourdieu's idea of the habitus can be retained', ...the stress must be put on his idea of improvisation, for improvisation no longer occurs within a relatively bounded set of thinkable postures but is always skidding 
and taking off, powered by the imagined vistas of mass-mediated master narratives (p.55-56).

Our data lead us to a very different conclusion. While we would certainly acknowledge the ways in which 'imagined vistas' are becoming open to a wider cross-section of society through the influence of the mass media, the reduction in cost of travel and the increasing inter-dependence of nations, the socially-embedded nature of our respondents’ decisions suggests strongly that habitus, with its emphasis on an individual's 'subjective expectations of objective probabilities’ (Bourdieu, 1977, p.95) remains a highly useful concept.

\section{Acknowledgements}

We are very grateful to: the British Academy, for funding the research; Helena Wilson, for conducting the interviews; and our 85 respondents, who gave up their time to be interviewed.

\section{$\underline{\text { References }}$}

Adams, R. and Allan, G. (1998) (eds) Placing Friendship in Context Cambridge, Cambridge University Press.

Appadurai, A. (1996) Modernity at Large. Cultural Dimensions of Globalization University of Minnesota Press. 
Bauman, Z. (1995) Life in Fragments. Essays in Postmodern Morality Oxford, Blackwell.

Beck, U. and Beck-Gernsheim, E. (1995) The Normal Chaos of Love Cambridge, Polity Press.

Bourdieu, P. (1977) Outline of a Theory of Practice Cambridge, Cambridge University Press.

Bourdieu, P. (1997) The forms of capital, in Halsey, A., Lauder, H., Brown, P. and Wells, A. (eds) Education: culture, economy, society Oxford, Oxford University Press.

Castells, M. (2001) The Internet Galaxy: reflections on the internet, business and society Oxford, Oxford University Press.

Chambers, D. (2006) New Social Ties. Contemporary Connections in a Fragmented Society Basingstoke, Palgrave.

Clark, T. (2006) A free lunch in Uppsala, The Guardian, 24 October 2006.

Conradson, D. and Latham, A. (2005) Friendship, networks and transnationality in a world city: antipodean transmigrants in London, Journal of Ethnic and Migration Studies, 31, 2, 287-305.

Department for Education and Skills (DfES) (2006) Prime Minister Launches Strategy to Make UK Leader in International Education. Press Notice 2006/0058, 18 April 2006 
Desforges, L. (2000) Travelling the World. Identity and Travel Biography, Annals of Tourism Research, 27, 4, 926-945.

Favell, A. (2008) Eurostars and Eurocities. Free movement and mobility in an integrating Europe Oxford, Blackwell.

Fechter, A-M. (2008) From 'Incorporated Wives' to 'Expat Girls': A New Generation of Expatriate Women? in Coles, A. and Fechter, A-M. (eds) Gender and Family Among Transnational Professionals London, Routledge.

Findlay, A., King, R., Stam, A. and Ruiz-Gelices, E. (2006) Ever reluctant Europeans: the changing geographies of UK students studying and working abroad, European Urban and Regional Studies 13, 4, 291 - 318.

Giddens, A. (1991) Modernity and Self-identity: self and society in the late modern age Cambridge, Polity Press.

Jamieson, L. (2005) Boundaries of Intimacy, in McKie, L. and Cunningham-Burley, S. (eds) Families in Society. Boundaries and Relationships Bristol, Policy Press.

Hayden, M. (2006) Introduction to International Education. International Schools and their Communities London, Sage. 
Heath, S. (2007) Widening the gap: pre-university gap years and the 'economy of experience’, British Journal of Sociology of Education, 28, 1, 89-103.

Hodkinson, P. (1998) Career decision making and the transition from school to work, in Grenfell, M. and James, D. (eds) Bourdieu and Education London, Falmer Press.

Institute of International Education (2007) Open Doors Fast Facts http://www.opendoors.iienetwork.org/file_depot/0-10000000/010000/3390/folder/58653/Fast+Facts+2007+Final.pdf (Accessed 29/8/08)

Kennedy, P. (2004) Making global society: friendship networks among transnational professionals in the building design industry, Global Networks, 4, 2, 157-179. King, R. (2003) International student migration in Europe and the institutionalisation of identity as 'Young Europeans’ in Doomernik, J. and Knippenberg, H. (eds) Migration and Immigrants: between policy and reality Amsterdam, Askant.

Mazlish, B. and Morss, E. (2005) A Global Elite? in Chandler, A. and Mazlish, B. (eds) Leviathans. Multinational Corporations and the New Global History Cambridge, Cambridge University Press.

Moore, F. (2008) The German School in London, UK: Fostering the Next Generation of National Cosmopolitans? in Coles, A. and Fechter, A-M. (eds) Gender and Family Among Transnational Professionals London, Routledge. 
Murphy-Lejeune, E. (2002) Student Mobility and Narrative in Europe. The new strangers London, Routledge.

Ong, A. (1999) Flexible Citizenship: the cultural logics of transnationality Durham, Duke University Press.

Pimpa, N. (2005) A family affair: the effect of family on Thai students' choices of international education, Higher Education 49, 431-448.

Putnam, R. (2001) Bowling Alone: the collapse and revival of American community New York, Simon and Schuster Ltd.

Reay, D., David, M. and Ball, S. (2005) Degrees of Choice. Social class, race and gender in higher education London, Trentham Books.

Rivzi, F. (2000) International Education and the Production of Global Imagination, in Burbules, N. and Torres, C. (eds) Globalisation and Education. Critical Perspectives New York, Routledge.

Shepherd, J. (2006) UK Students Drawn to US for Broad-Based Degrees, Times Higher Education Supplement, 4 August 2006.

Singh, P. and Doherty, C. (2008) Mobile students in liquid modernity. Negotiating the politics of transnational identities, in Dolby, N. and Rizvi, F. (eds) Youth Moves. Identities and education in global perspective New York, Routledge. 
Singh, M., Rizvi, F. and Shrestha, M. (2007) Student mobility and the spatial production of cosmopolitan identities, in Gulson, K. and Symes, C. (eds) Spatial Theories of Education. Policy and Geography Matters New York, Routledge.

Sklair, L. (2001) The Transnational Capitalist Class Oxford, Blackwell.

Spencer, L. and Pahl, R. (2006) Rethinking Friendship. Hidden solidarities today Princeton University Press.

Sussex Centre for Migration Research (2004) International Student Mobility. University of Sussex.

Szelenyi, K. (2006) Students without Borders? Migratory decision-making among international graduate students in the US, in Smith, M. and Favell, A. (eds) The Human Face of Global Mobility New Brunswick, NJ, Transaction Publishers.

Urry, J. (2007) Mobilities Cambridge, Polity Press.

Vincent, C. and Ball, S. (2006) Childcare, Choice and Class Practices. Middle class parents and their children London, Routledge.

Waters, J. (2007) 'Roundabout routes and sanctuary schools': the role of situated educational practices and habitus in the creation of transnational professionals, Global Networks, 7, 4, 477-497. 
Wiers-Jenssen, J. (2008) Does higher education attained abroad lead to international jobs?, Journal of Studies in International Education, 12, 2, 101-130.

Willis, K. and Yeoh, B. (2008) 'Coming to China Changed my Life': Gender Roles and

Relations among Single British Migrants, in Coles, A. and Fechter, A-M. (eds) Gender and Family Among Transnational Professionals London, Routledge. 